\title{
Interaction of the Canadian Association of Gastroenterology with industry
}

\author{
Clifford Ottaway MD PhD FRCPC, Lloyd R Sutherland MD FACP FRCPC
}

$\mathrm{T}$ he interaction of professionals, professional associations and universities with the pharmaceutical industry is under intense scrutiny (1-9). Throughout the 1990s, the relationship of the Canadian Association of Gastroenterology (CAG) with the pharmaceutical industry was guided by a document entitled Guidelines Regarding the Conduct of the Canadian Association of Gastroenterology with the Pharmaceutical and Manufacturing Industries. That document was written at a time when the principal activity of the CAG was its participation in the annual meetings of the Royal College of Physicians and Surgeons of Canada. The research and educational programs of the CAG have had great benefit from the interactions of the CAG with a variety of industries over many years, but the reader will know that the extent of research and educational activities of the CAG has grown enormously.

In 2000, the governing board of the CAG charged the ethics committee with reviewing its policy for interactions of the CAG with the pharmaceutical industry. The ethics committee (Dr Jeff Axler, Dr Anne-Marie Griffiths, Dr CA Ottaway) reviewed the existing policy, the emerging literature and the position of the Canadian Medical Association (CMA), and made recommendations to the governing board for a new position statement regarding CAG-industry interactions (Appendix 1).
This position statement was discussed in detail at CAG board meetings in late 2000 and early 2001, but final approval was deferred while the CMA was updating its policy on physicians and the pharmaceutical industry. That policy was adopted by the CMA during 2001, and the position statement regarding CAG-industry interactions was adopted by the CAG governing board at its meeting November 24, 2001.

This position statement is coherent with the code of ethics of the CMA, and the CMA policy on physicians and the pharmaceutrical industry. It would not be appropriate for the CAG to adopt policies that would place its members, many of whom are physicians, in a position that would conflict with the policies of the CMA. The CAG recognizes that, in the complexity of modern professional life, situations regularly arise in which primary and secondary interests, and primary and secondary obligations, coexist. As Korn (10) observed:

Conflicts of interest are ubiquitous and inevitable in academic life; indeed in all professional life.

The challenge... is not to eliminate them, which is fanciful and would be inimical to public policy goals, but to recognize and manage them sensibly and effectively. 
With this position, the CAG has adopted a policy of disclosure of all industrial relationships in its educational activities, including the annual Canadian Digestive Diseases Week (CDDW) and in any publication endorsed by the CAG, including The Canadian Journal of Gastroenterology. For the purposes of this policy, 'industry' includes the pharmaceutical manufacturers as well as any manufacturers of medical devices or nutritional products. The purpose of full disclosure is to make all industrial relationships explicit and transparent.

The CAG has acted upon this position. Speakers and organizers of CDDW 2002 have been asked to complete disclosure statements. Furthermore, the CAG board decided that, effective immediately, all members of the CAG board, as well as the Editor-in-Chief and Associate Editors of The Canadian Journal of Gastroenterology, shall disclose industrial relationships on an annual basis (Appendix 2).

\section{REFERENCES}

1. Wazana A. Physicians and the pharmaceutical industry: Is a gift ever just a gift. JAMA 2000;283:373-80.

2. Tenery RM. Intercations between physicians and the health care technology industry. JAMA 2000;283:391-3.

3. DeAngelis CD. Conflict of interest and the public trust. JAMA 2000;284:2237-8.

4. Feldman W. The pharmaceutical industry/L'industri pharmaceuttique. Ann R Coll Physicians Surg Can 2000;33:404-5.

5. Williams AH, Rowell M. Private enterprise and public good: Ethical issues in the funding of clinical research. Ann R Coll Physicians Surg Can 1999;32:227-31.

6. Wolf LE, Lo B. Ethical issues in clinical research: An issue for all internists. Am J Med 2000;109:82-5.

7. Lewis S, Baird P, Evans RG, et al. Dancing with the porcupine: rules for governing the university-industry relationship. CMAJ 2001;165:783-5.

8. Davidoff F, DeAngelis CD, Drazen JM, et al. Sponsorship, authorship and accountability. CMAJ 2001;165:786-8.

9. Moses H, Martin JB. Academic relationships with industry: A new model for biomedical research. JAMA 2001;285:933-5.

10. Korn F. Conflicts of interest in biomedical research. JAMA 2000;284:2234-7.

\section{APPENDIX 1 \\ Canadian Association of Gastroenterology-industry interactions: Position statement (adopted November 2001)}

1. The Canadian Association of Gastroenterology adheres to the Canadian Medical Association code of ethics.

2. The Canadian Association of Gastroenterology adheres to the Canadian Medical Association Policy on Physicians and the Pharmaceutical Industry.

3. The Canadian Association of Gastroenterology expects full disclosure* of all Industrial relationships in all Canadian Association of Gastroenterology-endorsed Continuing Medical Education (CME) events, such that:

a) Organizers of Canadian Association of Gastroenterology-endorsed CME events shall disclose all financial affiliations with Industrial sponsors to the participants in that event, and

b) Organizers of Canadian Association of Gastroenterology-endorsed CME events shall provide to the Canadian Association of Gastroenterology Executive a complete statement of account for the event within 45 days of completion of the event.

c) A financial summary of Canadian Association of Gastroenterology-endorsed CME events shall be presented at the Annual General Meeting of the Association.

c) Presenters and speakers at Canadian Association of Gastroenterology-endorsed CME events shall disclose all Industry associations and interests to the organizers and participants in the event.

4. The Canadian Association of Gastroenterology expects full disclosure* of all Industrial relationships by the authors of manuscripts published in Canadian Association of Gastroenterology-endorsed publications.

${ }^{*}$ An example of a disclosure statement is "Author ( $A$ ) has received support from Industrial sponsors $(X, Y, Z$, etc) and has acted as a consultant to $(X 1, Y 1, Z 1$, etc)" 


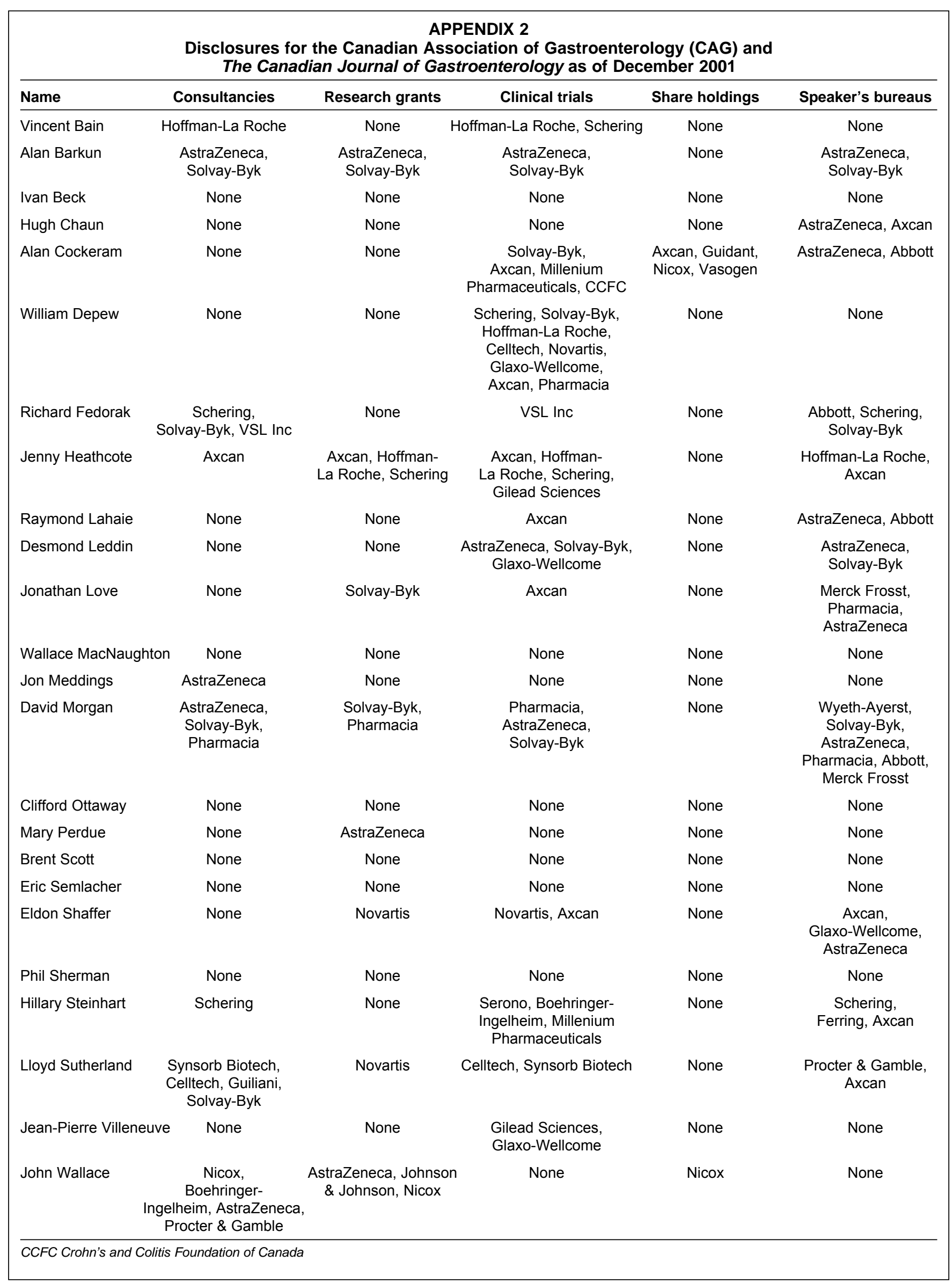




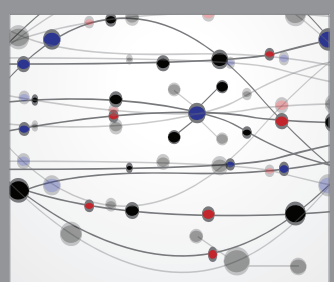

The Scientific World Journal
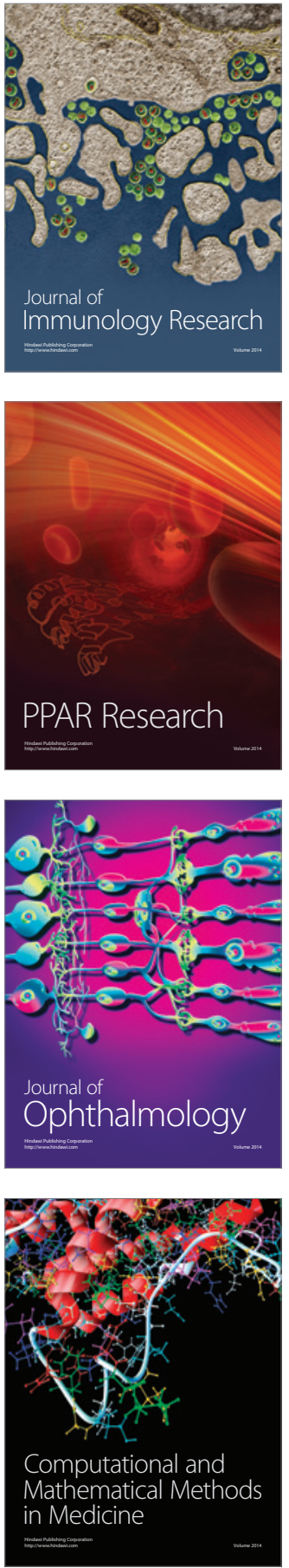

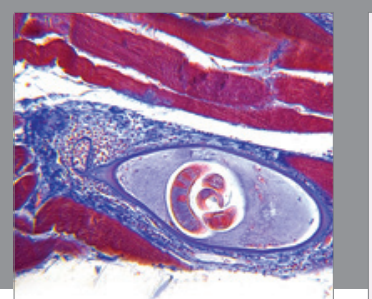

Gastroenterology Research and Practice

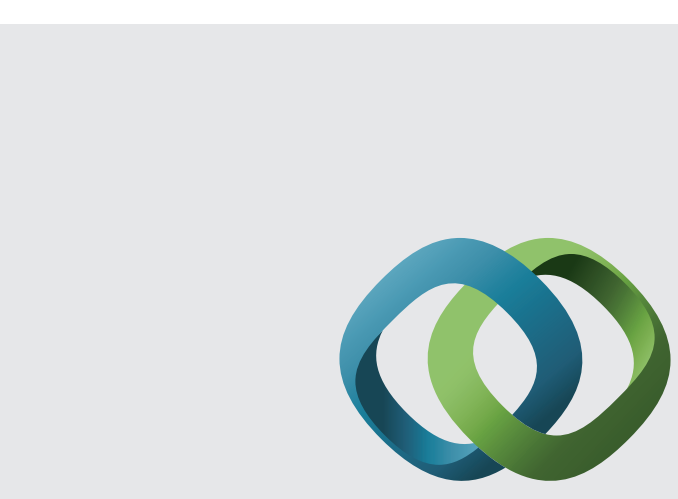

\section{Hindawi}

Submit your manuscripts at

http://www.hindawi.com
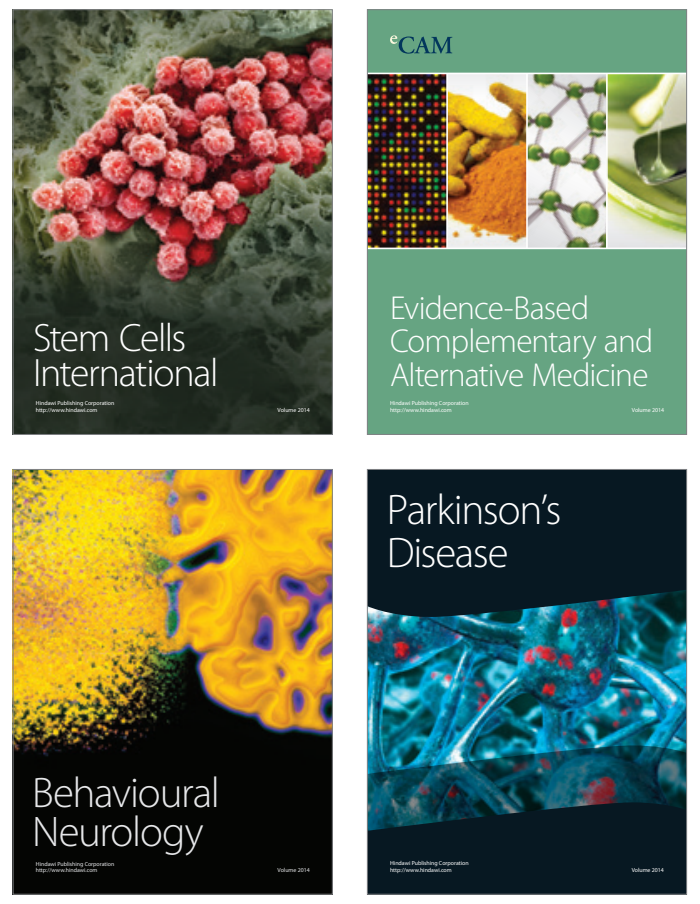
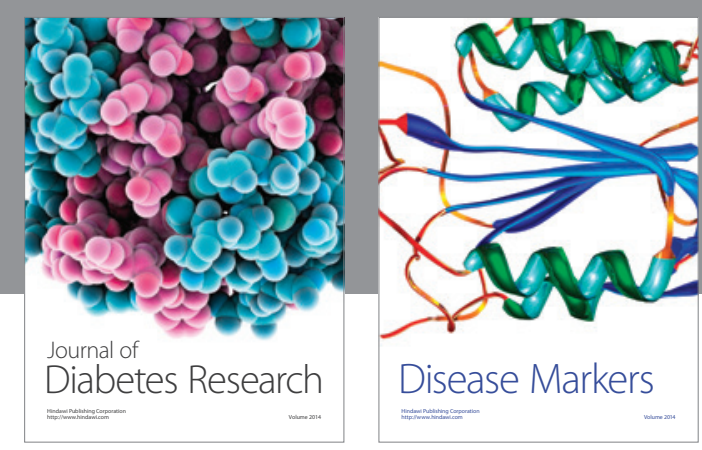

Disease Markers
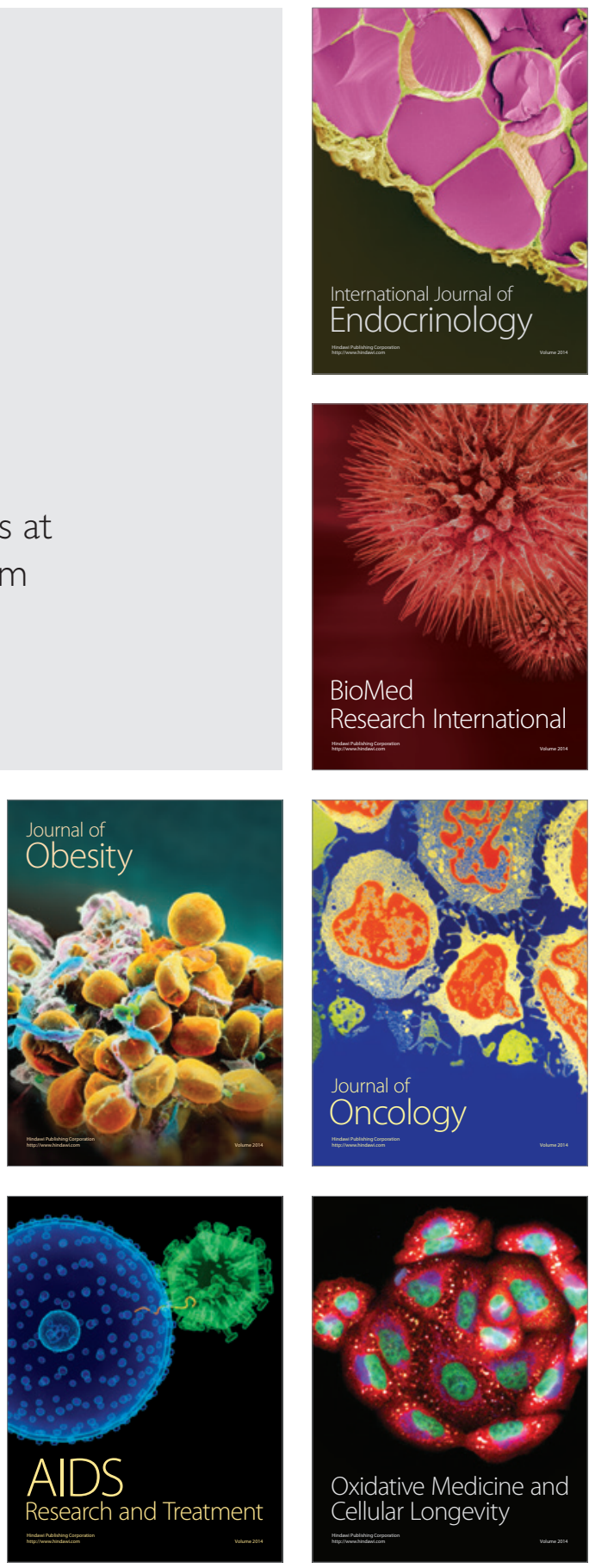